\title{
Response to Ebola Virus Disease Outbreak in Nigeria, West Africa: The Zaria experience
}

\author{
Aisha Abubakar*, Kabir Sabitu, Mohammed Nasir Sambo, Abdulrazaq Gobir, \\ Sani Ibrahim, Sulaiman Bashir and Ahmad Umar
}

Department of Community Medicine, Ahmadu Bello University Zaria, Zaria, Nigeria

\section{Objective}

To assess the formation and function of a joint committee of the Ahmadu Bello University (ABU) and the Ahmadu Bello University Teaching Hospital (ABUTH) to prevent and control EVD in Zaria and the North West sub region of Nigeria.

\section{Introduction}

The Ebola Virus Disease (EVD) outbreak in West Africa was unprecedented in spread and its attendant response. There were over 15,000 confirmed cases and over 9,000 suspected cases. The response to the outbreak was massive within Africa and beyond. The outbreak in Nigeria affected 19 people and led to 7 deaths (CFR 37\%). There were more than 891 contacts of these cases under surveillance as of $23^{\text {rd }}$ September 2014. Nigeria was declared EVD free by the World Health Organization in October 2014.

Nationwide there was targeted preparedness to prevent and control EVD. In Zaria, this led to the formation of a joint committee of the Ahmadu Bello University (ABU) and the Ahmadu Bello University Teaching Hospital (ABUTH) to prevent and control EVD in Zaria and the sub region as a whole.

\section{Methods}

A joint multidisciplinary committee was formed by $\mathrm{ABU}$ and ABUTH with representatives from the Department of Community Medicine, Internal Medicine, Nursing sciences, Veterinary Public Health, Medical Microbiology, Mass Communication, Directorate of Public Affairs ABU Zaria, General Administration and Management services division ABUTH, the University Health Services and the Centre for Disease Risk Management under the Department of Geography. Four subcommittees were created steered by the main committee. The subcommittees were Surveillance; Case Management; Infection Control and Social and Mass mobilization subcommittees

\section{Results}

The committee conducted seminars and trainings in case management, surveillance and infection control. Mass media campaigns included radio jingles production and airing as well as production of flyers and posters on EVD prevention and control. There was a phone-in live radio programme. A screening exercise for raised temperature was conducted using laser thermometers at main entry points. A case of suspected EVD was managed who turned out to be a case of dengue haemorrhagic fever.

\section{Conclusions}

The committee was enriched by its multidisciplinary nature and a blueprint for the control and prevention of EVD was developed in line with national and global standards. The committee was hampered with lack of funds to implement fully the blueprint for the prevention and control of EVD in Zaria and its environs. The committee transformed into the ABU/ABUTH Epidemic Preparedness and Response Committee after the outbreak was over to address other emerging epidemics.

\section{Keywords}

Ebola Virus Disease; Prepareness; prevention

\section{Acknowledgments}

The Ahmadu Bello University Zaria, Nigeria

The Ahmadu Bello University Teaching Hospital Zaria

\section{References}

ABU/ABUTH Joint Committee For The Prevention And Control Of Ebola Virus Disease (ABUPACE) Blueprint For Prevention And Control Of Ebola Virus Disease In ABU/ABUTH Zaria 2014. Pages 1-44

World Health Organization. WHO declares end of Ebola outbreak in Nigeria www.who.int/mediacentre/news/statements/2014/nigeriaends-ebola/en/

\section{*Aisha Abubakar}

E-mail: draishau@yahoo.com 